Departamento de Ciência e Tecnologia, Secretaria de Ciência, Tecnologia e Insumos Estratégicos, Ministério da Saúde

Correspondência | Correspondence: Decit - Departamento de Ciência e Tecnologia do Ministério da Saúde Esplanada dos Ministérios Bloco G sala 845 70058-900 Brasília, DF, Brasil

Texto de difusão técnico-científica do Ministério de Saúde.

\section{Rede Dengue: inovação da abordagem e da gestão em pesquisa à saúde}

\section{Dengue Network: innovation in research and management approach to health}

O aumento da complexidade populacional brasileira, associada à dinâmica das doenças prevalentes ou inseridas no âmbito social, exige respostas eficientes da gestão pública.

O processo de pesquisa e as formas de fomento, que envolvem financiamento e controle, fazem parte desse esforço conjunto. Seguindo os princípios de economicidade, racionalização de tempo, de pessoal e de verbas, não faz sentido estimular respostas derivadas do trabalho científico de grupos isolados de pesquisa, mas promover a colaboração entre diversas instituições com capacidade de desenvolverem estudos mais abrangentes e com potencial de resposta mais efetivo.

Com isso, novas iniciativas surgem dentro dos órgãos e autarquias federais e estaduais para maximizar respostas efetivas para o controle de agravos à saúde da população e para a melhoria ampla da atenção à saúde, segundo as diretrizes do Sistema Único de Saúde (SUS).

Desde 2002, o Ministério da Saúde fomenta programas e editais para a pesquisa em rede com foco nas doenças negligenciadas (malária, doença de chagas, dengue, leishmaniose, tuberculose, esquistossomose e hanseníase). Essas doenças prevalecem ou podem incidir sobre $90 \%$ da população mundial e mobilizam cerca de $10 \%$ do capital global destinado à pesquisa. $O$ primeiro cenário constituiu-se na Rede Tuberculose (Rede TB) e inspirou experiências como os editais de 2006 e 2008, que incluíram investigações multicêntricas sobre tais agravos em saúde pública. A partir da experiência da Rede TB, o Departamento de Ciência e Tecnologia do Ministério da Saúde (Decit/MS), junto ao Ministério da Ciência e Tecnologia (MCT), lançou o edital para formar a Rede de Pesquisa Dengue em 2009. A ação teve apoio do Conselho Nacional de Desenvolvimento Científico e Tecnológico (CNPq), além das Fundações de Amparo à Pesquisa (FAPs) de Minas Gerais, São Paulo, Rio de Janeiro, Bahia e Pernambuco.

\section{INVESTIGAÇÃO CIENTÍFICA SOBRE A DINÂMICA DA DENGUE}

A dengue foi reintroduzida no Brasil em 1976. Típica arbovirose (virose transmitida por artrópode), caracteriza-se como doença tropical negligenciada. $\mathrm{O}$ vírus da dengue é transmitido em um ciclo envolvendo humanos e mosquitos e tem o Aedes aegypti como vetor mais importante. A transmissão ocorre principalmente em áreas temperadas e tropicais de alcance do vetor e a disseminação do vírus ocorre mais freqüentemente durante o verão. O controle do vetor, que inicialmente parecia ser a melhor solução, mostrou-se ineficiente no Brasil nos últimos anos, seja pela interrupção dos programas de combate ao mosquito, seja pelo aparecimento de mosquitos e larvas resistentes a diversos inseticidas e larvicidas.

Até hoje, foram descobertos quatro sorotipos do vírus da dengue. No Brasil, os sorotipos 1 e 2 têm circulação simultânea em 18 estados. O sorotipo 3 foi encontrado no estado do Rio de Janeiro entre os anos de 1999 e 2000. Além do Brasil, o sorotipo 3 já foi detectado em 15 países. A ocorrência dos três sorotipos no País potencializa o risco de surgimento de epidemias de febre hemorrágica por dengue, sobretudo nas grandes metrópoles que tiveram epidemias por dois sorotipos. Já o sorotipo 4 está presente em dez países, incluindo Venezuela, Equador, Peru e, recentemente em risco epidêmico, no Brasil.

As principais questões que envolvem as pesquisas em dengue concentram-se nas grandes áreas investigatórias: dinâmica de infecção e controle (epidemiológico, entomológico e de vigilância em saúde pública); fisiopatogenia e preditores moleculares, genéticos e clínicos (pesquisas pré-clínicas); e diagnóstico, terapêutica e manejo clínico (investigações clínicas).

Mesmo com os grandes avanços de pesquisa em saúde no Brasil nos últimos dez anos, as pesquisas em doenças negligenciadas ainda priorizam alvos da área de 
dinâmica de infecção e controle. O número de projetos e trabalhos sobre a terceira geração de investigação em doenças instaladas na população, sobre vacinas, diagnóstico, terapêutica e manejo clínico, é incipiente para suprir as necessidades que possibilitariam avanços mais complexos dos serviços de saúde.

Forma-se, assim, um paradoxo: como explicar não ter alcançado o desenvolvimento mais avançado, relacionado à terceira geração, se há diversas e favoráveis iniciativas de fomento a pesquisas realizadas pelos últimos governos.

\section{COMPLEXIDADE DA DENGUE}

A complexidade da dengue evidencia-se de formas distintas ao longo do tempo.

Ao se analisar a incidência da doença nos últimos 20 anos (Figura 1), verificam-se momentos de controle da doença em 1999 e 2004, a partir de ações efetivas conseqüentes às políticas de saúde. No entanto, os picos subseqüentes não são proporcionais às ações de vigilância. Evidências epidemiológicas em estudos tentam mostrar contradições em regiões nas quais o Levantamento Rápido do Índice de Infestação do Aedes. aegypti (LIRAa) não indica precisamente o risco de infecção da dengue e, concomitantemente, os dados sobre a circulação viral.

Há carências de modelos que possam explicar a evolução da doença entre populações com variáveis demográficas semelhantes, mas que apresentam diferenças significativas na propagação viral. Além disso, necessita-se de explicações mais precisas sobre a interação do parasita com o vetor da dengue, bem como a fisiopatogenia, com evidências sólidas que possibilitem traçar perspectivas de incidência e re-infecção, principal razão dos casos hemorrágicos e, portanto, mais graves da doença.

A prova das necessidades inovadoras de descrição epidemiológicas da doença foi comprovada no lançamento da nova ferramenta para avaliar o risco de epidemias de dengue pelo Ministério da Saúde. Cinco critérios associados, incluindo o uso do LIRAa, serão utilizados como parâmetro para refletir informações mais precisas sobre o quadro da doença nas comunidades brasileiras. Grande parte dos projetos da Rede Dengue correlaciona-se aos interesses dos programas e políticas de saúde tutelados pelo Estado. Os conhecimentos gerados pela Rede Dengue oferecerão importante arcabouço para a evolução das iniciativas relacionadas ao combate e ao controle da dengue no território nacional.

\section{HISTÓRICO DE PESQUISA EM DENGUE NO BRASIL}

Os primeiros registros da doença no Brasil datam do início do século XIX, afetando principalmente as populações urbanas menos favorecidas e escravos rurais.

Um dos maiores ícones da história nacional relacionado à pesquisa em saúde pública e ao controle de epidemias foi Dr. Oswaldo Cruz. O médico-sanitarista realizou no Rio de Janeiro a primeira erradicação da dengue, junto com febre amarela, na capital, emitindo os resultados da ação planejada ao então presidente Afonso Pena no dia 8 de março de 1907.

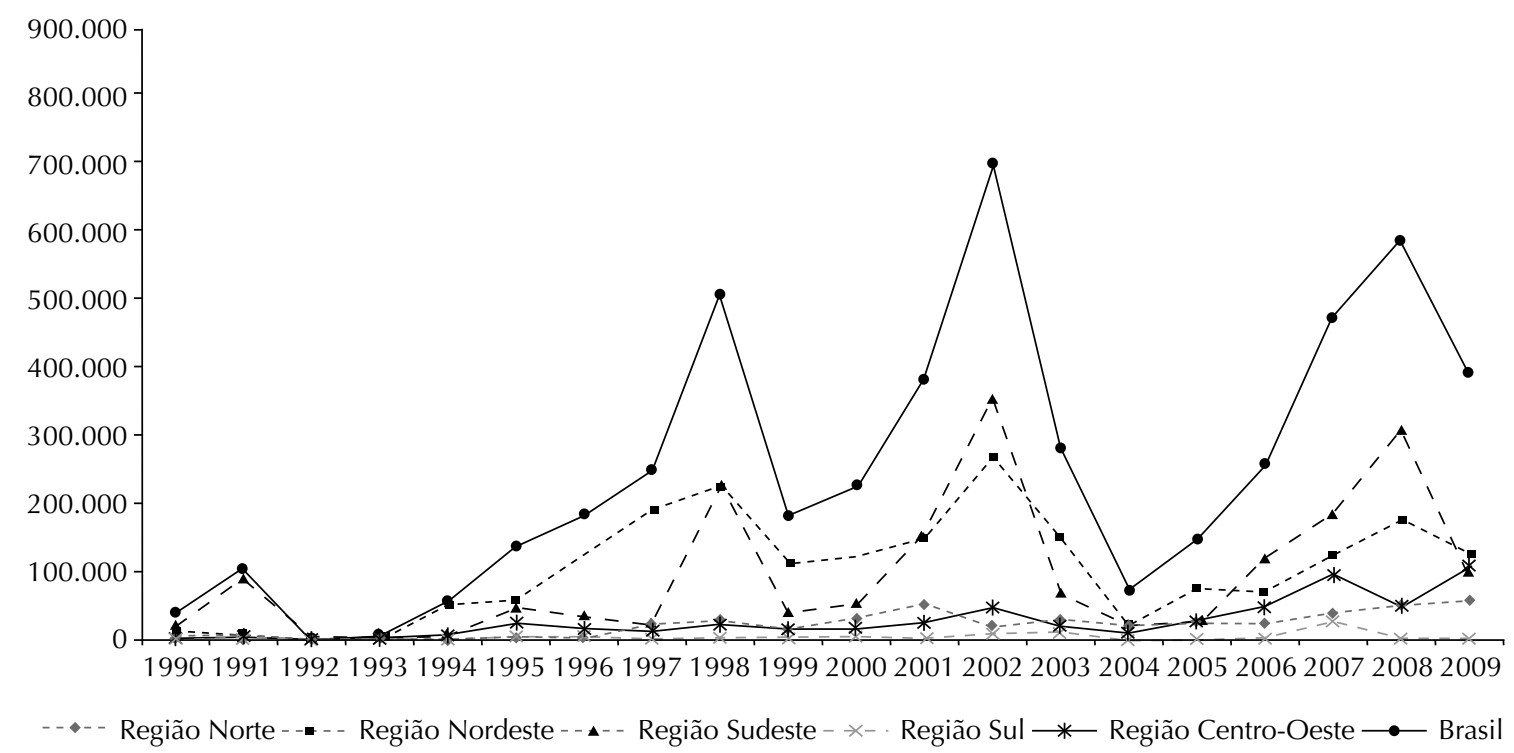

Fonte: Ministério da Saúde

Figura 1. Evolução da incidência da dengue (quadro epidemiológico geral). Brasil, 1990-2009 
Desde então, devido à falta de interesse direto de investimentos em pesquisa por parte da iniciativa privada no Brasil, a geração de produtos e serviços para o combate à dengue compete ao setor público em três esferas: federal, estadual e, de forma estrita, municipal.

A partir de 1980, vários grupos de pesquisa sobre a dengue se estabeleceram, configurando centros especializados na geração de conhecimentos específicos sobre a doença. Constatava-se, todavia, tendência ao isolamento desses grupos, bem como concentração de pesquisas nas áreas básicas, em detrimento daquelas direcionadas aos serviços de saúde e controle da endemia. Esse fato mostrou a necessidade de uma gestão pública para promover pactuação entre os grupos de pesquisa existentes, tanto os consolidados como os emergentes. Confirma-se a tendência mundial de estimular as chamadas Redes de Pesquisa não só embasadas na execução cooperativa. Associam-se novas referências de controle e condicionalidade ao financiamento vinculado à existência e à manutenção da Rede entre pesquisadores e instituições especializadas. A diretriz maior das Redes de fomento à pesquisa é concretizar o produto macro da atividade científica às reais necessidades que se manifestam no cotidiano social.

\section{REDE DE PESQUISA: GESTÃO E PRODUÇÃO CIENTÍFICA NO SUS}

As Redes de Pesquisa constituem-se por uma forma de articulação do conhecimento que ultrapassa o discurso acadêmico/científico, no qual grupos de pesquisa estiveram predominantemente ancorados. Redes como as vinculadas ao Programa de Apoio a Núcleos de Excelência do CNPq/MCT (Pronex) e aos órgãos públicos de âmbito nacional passam a constituir nova possibilidade de produção do conhecimento científico. Prima-se por pesquisas não mais determinadas pelas limitações materiais locais (uma universidade ou grupo), mas que se alinhem com diretrizes consideradas estratégicas nacional e/ou internacionalmente e com suas conseqüentes e mais amplas condições materiais.
Em 2009, com as diretrizes traçadas para a formação de redes de pesquisa, foi lançado o Edital Rede Malária (CNPq No 09/2009 - Pronex) e selecionados 16 projetos para o trabalho cooperativo formal, em pleno processo de execução.

Todas as etapas, desde o planejamento estratégico, forma de instrumentalização convocatória, seleção, apreciação e controle de execução, moldaram as propostas de redes futuras, inclusive a Rede Dengue.

\section{REDE DENGUE: FORMALIZAÇÃO DA INTERAÇÃO PESQUISADORES/ INSTITUIÇÕES}

O Ministério da Saúde, por intermédio do Departamento de Ciência e Tecnologia da Secretaria de Ciência e Tecnologia e Insumos Estratégicos, em parceria com o MCT/CNPq e 20 FAPs, lançou o Edital MCT/CNPq $N^{o}$ 073/2009 - Pronex - Rede Dengue à pesquisa em saúde em âmbito nacional para promover a sustentação e o fortalecimento do esforço nacional em ciência, tecnologia e inovação em saúde.

Das 42 propostas de projetos de pesquisa submetidos, de todos os estados brasileiros, 15 foram selecionados, conforme critérios estabelecidos pelas resoluções normativas do CNPq. Cerca de R \$ 8,7 milhões foram destinados para grupos de pesquisa, com proporção igualitária de fonte de financiamento entre o Decit/MS, CNPq e as citadas FAPs que permaneceram na Rede por interesse direto ou indireto no produto dessa seleção.

Nesse edital, ainda que tenha havido concentração maior de pesquisas nos campos da epidemiologia, vigilância, educação em saúde e controle de vetores, também foram fomentadas investigações nas áreas críticas da clínica, da produção de vacinas e do controle endêmico. Os 15 projetos aprovados distribuíram-se entre investigações de epidemiologia e controle da infecção (nove projetos), e estudos pré-clínicos (seis projetos), na busca de vacinas e substâncias potencialmente usadas para futuras drogas ou insumos diagnósticos para o combate à doença (Figura 2).

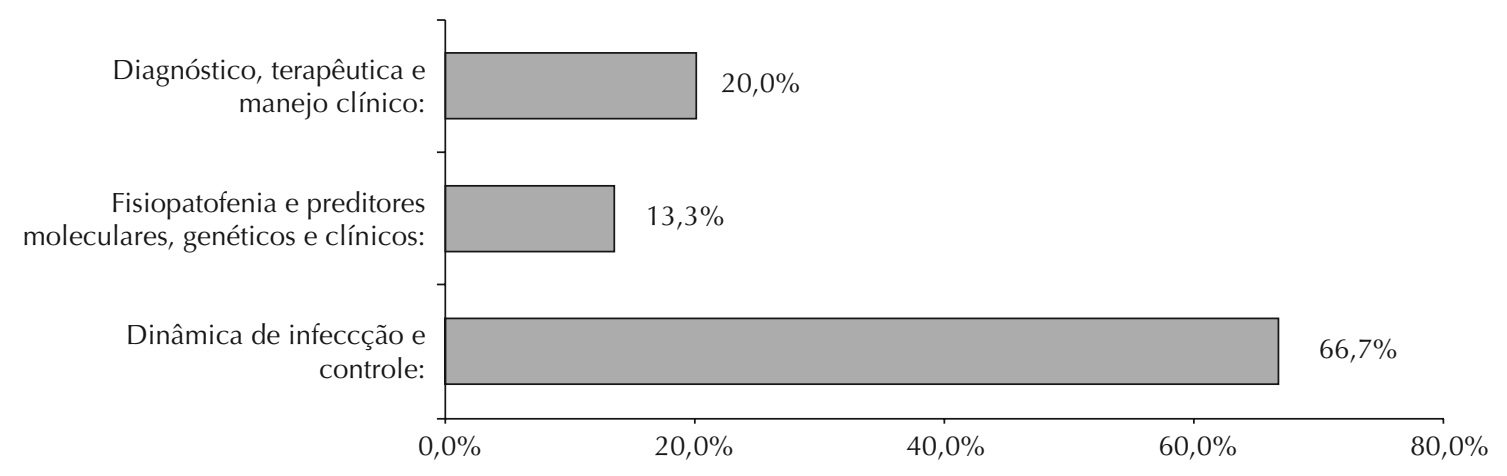

Figura 2. Distribuição dos projetos selecionados para formação da Rede Dengue, por linhas de pesquisa 
Em pesquisas sobre controle vetorial e vigilância epidemiológica, fatores primários para o controle de surtos de arbovirose são amplamente abordados para desenvolver novas tecnologias de controle do Ae. aegypti em ambientes urbanos. Em paralelo, investiga-se a análise da competência/capacidade vetorial, o que possibilita a melhor predição do surgimento de epidemias. Várias dessas iniciativas de pesquisa incluem ações educativas que envolvam a doença e a colaboração popular para prevenir a disseminação do mosquito transmissor.

Há trabalhos mais específicos, mas de igual importância, que buscam responder a questões sobre o uso de inseticidas que não ocasionem impactos ecológicos, associados a fatores de resistência do mosquito. Os resultados serão importantes, uma vez que boa parte dos recursos envolvidos no combate à dengue destinase à aplicação de tais insumos em regiões com alta incidência da doença.

Outras linhas de investigação buscam novas estratégias para vigilância e análise epidemiológica. A dengue possui características próprias e envolve grande número de variáveis intrínsecas à patologia e outras extrínsecas, a exemplo de fatores ambientais, invasão de categorias silváticas do vetor em ambiente urbano e capacidades distintas de transmissão entre populações do Ae. aegypti.

Entre as competências a serem adquiridas a partir das pesquisas da Rede Dengue, ambiciona-se a busca de modelos matemáticos que formalizem a dinâmica da população vetorial e da doença entre as áreas urbanas e naturais. Os resultados podem colaborar para diminuir o impacto econômico da endemia, associados à maior efetividade de ações de saúde em áreas com surto da dengue e nas que sofrem o risco de epidemia.

A segunda grande área de pesquisa representa número menor de estudos e compreende as investigações pré-clínicas. As propostas envolvem a busca de alvos moleculares de diferentes naturezas químicas que representem esperanças de vacinas, drogas para terapias efetivas e processos mais rápidos e menos dispendiosos de diagnóstico.

Há dificuldade natural na busca de tais alvos para dengue. Circulam quatro sorotipos diferentes do vírus da dengue, o que impede a obtenção de insumos "generalistas" que possuam eficiência de prevenção ou cura. Isso explica o fato de essa doença de convívio antigo com a espécie humana não possuir tratamento específico e vacinas eficazes.

Dos projetos aprovados, vários são os que testam alvos genéticos e protéicos do vírus, configurando a possibilidade de vacinas ou o "pool" de vacinas associadas, e outros desenvolvem pesquisas para a descoberta de mecanismos fisiopatológicos e bioquímicos, envolvendo a infecção e o desenvolvimento de sintomas da dengue.
A experiência da Rede Dengue já demonstra seu caráter de união de esforços e sua abrangência. São 278 pesquisadores em diferentes níveis, diretamente envolvidos nos projetos. Associam-se mais de 300 pesquisadores de 58 instituições nacionais e 19 internacionais que, de maneira indireta, participam da rede e contribuem para efetivar os resultados de pesquisa desse importante tema.

A maior parte dos projetos qualificados foi apresentada pelo respectivo coordenador responsável em reunião com gestores, técnicos e coordenadores de pesquisas envolvidos na Rede Dengue.

Dessa maneira, redes de pesquisa representam um avanço na administração pública para a melhoria da implementação de investimentos e retorno de resultados exponenciais. Esses resultados podem, de fato, refletirse em melhorias das condições de saúde das populações afetadas, com maior agilidade por parte dos serviços para o controle dos transmissores e maior efetividade das ações de profilaxia.

\section{AGREGAÇÃO DE VALOR SOB PERSPECTIVAS NACIONAIS E INTERNACIONAIS}

Nos últimos anos, a imprensa enfatizou as falhas nos serviços de assistência aos pacientes infectados com dengue em diversas regiões do Brasil, em especial os quadros regionais nos estados do Sudeste. Em contraposição, segundo a Organização Mundial de Saúde e relatórios internacionais, o Brasil é um dos principais países de financiamento em pesquisas sobre doenças negligenciadas, incluindo a dengue. Nesse caso, o Brasil ocupa a terceira posição entre os doze maiores fundos fomentadores, de acordo com o G Finder, 2009.

A Rede Dengue merece divulgação e apoio como demonstração de resposta da comunidade acadêmica e da gestão pública à situação epidemiológica agravada. Com ela, promove-se o desenvolvimento de ciência e tecnologia essencialmente nacionais e que consolidam ações de resposta mais imediata a surtos da dengue concomitantes, com menores custos de aquisição de insumos e procedimentos quando comparados a versões importadas.

\section{ESTRATÉGIAS ÀS REDES DE PESQUISA: MISSÃO E VISÃO}

Sob as novas perspectivas da gestão, as redes de pesquisa até aqui projetadas servem de ensaio para o desenvolvimento de metodologias de fomento e controle às novas concepções de comunicação e colaboração entre o corpo acadêmico especializado do País. O sucesso de tal empreitada resultará em atração de novas fontes de financiamento e, conseqüentemente, novos colaboradores, como instituições e pesquisadores comprometidos com a geração de conhecimento. 
Estão em projeto novas ações de parcerias envolvendo FAPs, pesquisadores e instituições, ou seja, novas redes para doenças negligenciadas. Do ponto de vista tático, estas seguirão os mesmos moldes de convocação, seleção e organização das Redes Malária e Dengue.
Dessa forma, espera-se que novo arranjo organizacional configurado em rede de pesquisa sustente os estudos e promova um fluxo natural dos temas, para que trabalhos voltados à resolução de problemas sociais e de saúde pública possam ser vistos dentro do universo acadêmico brasileiro. 